\title{
Комплексный имидж государственной власти как инструмент социального управления
}

\author{
E. В. Мишон ${ }^{1 凶}$ \\ ${ }^{1}$ Воронежский государственный университет, Университетская пл., 1, \\ 394018, Воронеж, Российская Федерация
}

Для цитирования: Мишон E. В. Комплексный имидж государственной власти как инструмент социального управления // Вестник Воронежского государственного университета. Серия: Экономика и управление. 2021. № 1. C. 76-85. DOI 10.17308/econ.2021.1/3326

\begin{abstract}
Предмет. Практика последних лет демонстрирует тенденцию снижения доверия населения к деятельности органов власти. Дальнейшее формирование этого процесса недопустимо, поскольку в подобном случае работа всех государственных структур неэффективна даже при условии ее абсолютной целесообразности и обоснованности. Причины недоверия общественности к органам власти можно разделить на три группы: коммуникативные, организационные и культурно-исторические проблемы. Коммуникативные проблемы возникают из-за нарушений или игнорирования требований теории коммуникаций. Организационные сложности в подавляющем большинстве случаев связаны с низкой квалификацией специалистов, отвечающих за взаимодействие с обществом (обычно это PR-специалисты или специалисты по связям с общественностью). Культурно-исторические проблемы обусловлены доминированием в нашем обществе устоявшейся модели поведения граждан, которая стабильно воспроизводит ситуацию противостояния власти. На наш взгляд, первоочередного внимания требует наиболее значимая группа - коммуникационные проблемы.

Цели. Коммуникационные проблемы возникают вследствие неправильного позиционирования деятельности властных структур, т. е. из-за неумения доходчиво и аргументированно разъяснить значимость и целесообразность планируемых или уже реализуемых мер. Соответственно, необходимо в короткие сроки определить/разработать технологии, способы и инструменты, позволяющие ликвидировать коммуникационные барьеры, а в ряде случаев коммуникационные провалы, взаимодействия общественности и государственных структур.

Методология исследования. Для достижения поставленной цели применен авторский подход, в основе которого лежат принципы системности, гибкости, мобильности и адекватности (они послужили основой обоснования необходимости разработки комплексного имиджа). Теоретической базой служат труды отечественных и зарубежных ученых в области управления общественными отношениями. Используются методы исследования мягких систем: теоретическая типологизация, формальная экстраполяция, фактографические методы, основанные на анализе информации (метод аналогий, содержательный контент-анализ), форсайт-моделирование (технология работы с образами будущего).

Результаты. В целях повышения рейтинга доверия населения к деятельности государственных структур на основе изучения, систематизации и анализа причин и последствий коммуникативных провалов и барьеров эффективного взаимодействия между указанными коммутаторами предложен подход, базирующийся на предложенных автором принципах (системности, адекватности, гибкости, мобильности) и использовании такого инструмента социального управления, как имидж. Предложен и обоснован вариант разработки комплексного имиджа государственной структуры, включающий корпоративный и персональный имидж. Рекомендована технология его разработки, обеспечивающая комплексный подход к решению проблемы эффективного взаимодействия с использованием современных инструментов управления общественными отношениями.
\end{abstract}

Ключевые слова: коммуникативный барьер, рейтинг доверия, корпоративный имидж, персональный имидж, габитарный имидж, вербальный имидж.

(C) Мишон Е. В., 2021

Вестник ВГУ. Серия: Экономика и управление. 2021. № 1. С. 76-85. 


\section{Введение}

Для органов государственной власти как никогда ранее важно конструктивное сотрудничество с общественностью, что невозможно без доверия и взаимоуважения. Значимость этих составляющих подтверждается введением с февраля 2021 г. рейтинга доверия региональным властям, который занимает центральное место в ряду показателей эффективности работы глав региона.

Существующие группы проблем, приводящих к отторжению предложений государственных структур по различным вопросам социально-экономического развития, можно значительно сократить и даже устранить в случае грамотного обращения к общественному мнению, лидерам мнения. На данный момент обращение осуществляется через связи с общественностью. Они являются индикатором социально значимой информации применительно к деятельности органа государственной власти. С их помощью можно фиксировать, анализировать, планировать и направлять информационные потоки к конкретному субъекту власти или его полномочному органу.

Мы считаем, что предметом управления общественными отношениями является публичный капитал (паблицитный капитал), т. е. стоимость субъекта (юридического или физического лица) в глазах общества, другими словами, насколько значим для общества тот или иной субъект. Как известно, капитал представляет собой самовозрастающую стоимость, способную увеличить власть собственника. Потребительной стоимостью паблицитного капитала является имидж/репутация/престиж субъекта. В силу сказанного мы отводим имиджу значительную роль в укреплении доверия населения к деятельности государственных структур. Для ускоренного решения коммуникационной проблемы взаимодействия общества и государственных структур основное внимание, по нашему мнению, необходимо сконцентрировать на следующем.

Взаимодействие является эффективным, если органы власти в работе с населением опираются на такие принципы, как системность, адекватность, мобильность. Другими словами, работа по взаимодействию с населением должна вестись постоянно; ориентироваться на реальные проблемы общества; гибко изменяться и быстро реагировать на колебание запросов общества. Реализовать эти принципы может только двусторонняя коммуникация: властная структура - общественность.
Несколько слов необходимо сказать о коммуникационных моделях PR (англ. Public Relations).

Коммуникационная модель PR первого уровня, - publicity (представление) - ориентирована на распространение информации. Эта модель используется малыми организациями с простой системой управления. Второму уровню соответствует модель «общественная информация». Цель данного уровня - оптимальное распределение информации о субъекте. Модель третьего уровня называется «двусторонней асимметрией». Ее автор Э. Бернейз известный теоретик PR. Асимметрия указывает на то, что полученная от целевой аудитории информация использовалась исключительно в интересах организации для улучшения работы. Модель используется в организациях, в которых господствует децентрализованная система принятия решений и работает множество менеджеров, наделенных полномочиями принимать самостоятельные решения.

Четвертый уровень представлен моделью «двусторонней симметрии». Она отражает принцип: «любой бизнес в демократической стране начинается с общественного мнения и не может существовать без общественного согласия». На данном уровне достигается баланс между общественным мнением и субъектом, так как общественность вносит свой вклад в решение проблемы.

Две первые коммуникационные модели работают по принципу односторонней коммуникации, две последние - представляют двустороннюю коммуникация. В настоящее время модели с односторонней коммуникацией отмирают, уступая место моделям с двусторонней коммуникацией, поскольку две первые модели фактически являются манипуляционными. Очевидно, что никто не хочет подвергаться манипулятивным действиям. Проблема выбора модели функционирования - это во-первых, проблема самоопределения, во-вторых, проблема перспективы, прогнозируемости социальных последствий осуществленного выбора.

В России использовалась манипулятивная управленческая модель. По мере роста интенсивности общественных процессов, накопления социального опыта модель теряет эффективность. Ее использование вступает в конфликт с тенденцией прогрессивного развития, свойственной любой общественной структуре. Это нашло подтверждение в падении доверия к деятельности органов государственной власти. 
Таким образом, управление общественными отношениями с позиции органа государственной власти будет эффективным в случае использования двусторонней коммуникативной модели, которая наиболее полно отражает запросы современного общества и позволяет сформировать деятельность государственных структур сообразно общественным ожиданиям. Органы государственной и публичной власти заинтересованы не только в доведении целей, задач и результатов их деятельности до широкой общественности, но и в правильном восприятии и адекватной оценке реализуемых мероприятий. Данным целям в настоящее время служат коммуникации. В самом общем виде это каналы, обеспечивающие передачу и распространение информации, в том числе и связи с общественностью.

\section{Методология исследования и источники данных}

Несмотря на то что управление общественными отношениями - достаточно молодая наука и в нашей стране распространение получила по историческим меркам совсем недавно, можно говорить о важных наработках отечественных ученых в данной сфере научной деятельности. Также следует отметить активизацию публикаций по проблемам эффективного взаимодействия населения и органов власти $[9 ; 13 ; 18]$. Значительное место занимают проблемы формирования, функционирования и управления общественным сознанием $[1 ; 5 ; 6 ; 10 ; 14 ; 15]$, при этом в решении перечисленных выше проблем особое внимание уделяется средствам массовой коммуникации (далее - СМК/СМИ). Так, С. Г. Кара-Мурза практически в каждом исследовании делает акцент на том, что «СМИ - главный инструмент воздействия на общественное сознание» [5, с. 150].

К. С. Аратюнян считает, что значимым фактором формирования общественного сознания является информационное общество, а именно такой его элемент, как СМИ [1, с. 83]. Автор подкрепляет этот вывод аргументацией, ссылаясь на М. Кастельса, которому принадлежит введение термина «сетевое общество», приходящее, по его мнению, на смену постиндустриальному обществу. Особенностью сетевого общества является глобализация, которая в свою очередь невозможна без обширной и всесторонней деятельности СМИ, поскольку именно они создают условия для внедрения в общественное сознание неких стереотипов, «мифов» и т. п.
Представляется оправданным и своевременным интерес ряда авторов к возможностям современных коммуникаций - социальных сетей $[2 ; 4 ; 17 ; 18]$. Для данного исследования важным является приведенное в работе Д. А. Ильченко и В. П. Майковой обоснование зависимости между освещением проблемы в СМИ, ростом заинтересованности населения в информации по проблеме и формированием гражданской позиции [4]. В. В. Рокотянская приводит структуру общественного мнения $(\mathrm{OM})$ и рассматривает его разновидности. Она предлагает оценивать эффективность интернет-манипулирования общественным мнением в зависимости от таких факторов, как сохранение старых взглядов на новые статьи; регулярность обновления техник политического управления, развитие коммуникаций, появление новых общественных мнений, регулярное обращение к людям с целью выявления их мнения [18, с. 45]. Применительно к нашему исследованию представляется значимым выделение трех последних факторов.

Мы полностью согласны с позицией указанных выше авторов и считаем, что общественное мнение - главный объект внимания при построении доверительных отношений между общественностью и органами власти.

\section{Обсуждение результатов}

Связи с общественностью (PR-деятельность) распространяется на две ветви власти: законодательную и исполнительную. Судебная в силу своей специфики не предполагает вмешательства общественного мнения до момента принятия решения.

В субъектах РФ работу по налаживанию связей с общественностью выполняют государственные информационные агентства, управления по PR, лица, ответственные за связи с прессой, и другие функциональные подразделения местных органов власти.

Кроме традиционных способов взаимодействия с общественностью, выделяют альтернативные способы: референдум; ежегодные доклады, новостные письма, публикации; награды, получаемые гражданами, и награды от групп населения, получаемые чиновниками; связи с местными ассоциациями; культурные мероприятия. С позиции нашего исследования важными представляются такие альтернативные способы взаимодействия, как связи с местными ассоциациями, культурные мероприятия, поскольку происходит личный контакт представителей общественности и госу- 
дарственных структур. От того, насколько значимыми будут барьеры общения или будут ли они вообще, зависит оценочное общественное мнение, т. е. какой знак (позитивный или негативный) отразит общественное мнение по результатам встреч.

Преодолеть коммуникативные барьеры, в том числе межличностного общения, помогает такая важная составляющая рационального социального управления, как имидж.

Во-первых, имидж позволяет ускорить достижение поставленной цели за счет более эффективного управления (через убеждение, внушение, мнение) и расширения сферы влияния путем привлечения новых и удержания уже имеющихся целевых аудиторий. Это инструмент достижения стратегических целей.

Во-вторых, это инструмент конкурентной борьбы. Он возникает (стихийно или целенаправленно) там, где существует конкуренция.

Существенно изменить имидж достаточно сложно. Очевидно, что носитель имиджа выиграет, если его имидж не потребует изменений или корректировки и будет сразу «работать» на результат. Самостоятельно создать эффективно действующий образ не просто. Пока это удалось, пожалуй, только В. В. Жириновскому.

Учитывая, что потребность в имиджмейкерстве сформировалась относительно недавно, накопленный отечественный опыт ${ }^{1}$ по разработке и внедрению имиджа можно характеризовать как значительный. Работы [3; 7; $13 ; 14 ; 15 ; 22]$ - лишь небольшая часть исследовательского массива. Однако научные труды, посвященные имиджу государственных структур, встречаются не часто. Как правило, рассматривается и анализируется имидж корпораций, крупных финансовых структур, медийных лиц (обычно политических деятелей). При разработке рекомендаций по конструированию комплексного имиджа мы учитывали мнение И. В. Маслова относительно значимости «стратегии самопрезентации», применения различных тактик информирования, а также позиционирования стереотипов восприятия как основной проблемы формирования позитивного имиджа органа исполнительной власти.

Приступая к разработке имиджа, следует помнить, что функции имиджа (политическая, экономическая, эстетическая, социально-пси-

${ }^{1}$ Обращение к зарубежному опыту имиджмейкинга, его копирование не дали положительных результатов, что наиболее ярко отразила предвыборная кампания Б. Н. Ельцина в 1996 г. хологическая, контактная, социальной идентификации, установления доверия) и их максимально полная реализация чрезвычайно важны для взаимодействия органов государственной власти с общественностью и могут значительно влиять на ход социально-экономического и политического развития.

Для эффективного взаимодействия органа власти с общественностью мы предлагаем использовать комплексный имидж, включающий позитивный корпоративный имидж и персональный имидж сотрудника государственной власти.

В современной России имидж все больше становится значимым способом установления доверительных отношений между общественностью и органом власти. Значимость корпоративного имиджа государственной власти на данный момент достаточно обоснована. Однако, по нашему мнению, он должен существовать в паре с персональным имиджем сотрудника, реализующего управленческие решения, действующего от имени властных структур, поскольку сотрудник органа власти автоматически становится объектом внимания общественности и оценочное мнение играет не последнюю роль в присвоении знака плюс или минус действиям государственных структур.

Как коммуникативная структура имидж должен обеспечить точность передачи информации, совпадение знаковых систем коммуникатора и получателя сообщения.

При разработке персонального имиджа сотрудника власти важно учитывать такие группы черт, как индивидуально-личностные, социальные, личностно-энергетические, социально-энергетические, социально-нравственные.

Алгоритм формирования имиджа достаточно универсален и применим, по мнению автора, как к организации, так и к индивиду с определенной корректировкой, учитывающей специфику субъекта имиджа² . Однако, формируя имидж конкретного сотрудника органа государственной власти, мы считаем, следует уделить особое внимание таким видам имиджа, как вербальный и габитарный, поскольку они в наибольшей степени реализуют принципы адекватности, мобильности, гибкости.

Вербальный имидж в самом общем виде это манера говорить, словарный запас, интонации, логика рассуждения, т. е. отражение наличия или отсутствия индивидуально-лич-

${ }^{2}$ В ряде работ отражена иная позиция, однако это предмет отдельного исследования. Мы лишь ограничимся фиксацией позиции данного исследования. 
ностных, социальных, личностно-энергетических, социально-энергетических черт ${ }^{3}$.

Инструментом формирования вербального имиджа целесообразно выбрать самопрезентацию, позволяющую выработать необходимые навыки. В России интерес к ней возник относительно недавно и продиктован новыми экономическими условиями функционирования общества: переходом к рыночной модели хозяйствования, которая распространяет конкурентные условия не только на производственную, но и на социальную сферу. В современных условиях не только юридическое лицо, но и индивид должен быть конкурентоспособным, т. е. демонстрировать наличие (реальное или мнимое) наиболее востребованных качеств.

На данный момент перечень работ по выработке навыков самопрезентации достаточно внушительный. Коротко скажем, что для приобретения необходимых навыков следует обратиться к теоретическим основам самопрезентации и приложить достаточно усилий для отработки теоретических знаний на практике. С позиции практического использования самопрезентация - это навык ознакомления окружающих с собственной личностью, акцент делается на имеющихся достоинствах видеоаудиокачеств. С позиции социального управления это эффективный инструмент формирования позитивного образа.

Габитарный имидж можно рассматривать как сумму визуальных характеристик субъекта - сотрудника (прическа, осанка, походка, рост, вес, цвет волос, одежда и обувь, аксессуары), т. е. это источник оценочного мнения, возникающего на основании внешнего вида. Значение габитарного имиджа мы объясняем тем, что он в состоянии обеспечить требуемое (заранее заданное) восприятие субъекта и подчеркнуть его индивидуальность, отражающую востребованные на данный момент обществом характеристики (черты личности). Данный вид имиджа может указывать на присутствие таких важных черт, как социальные, социально-нравственные.

Относительно одежды надо учитывать следующее. Именно одежда наиболее ярко отражает такие социальные и социально-нравственные черты носителя, как высокие моральные качества, позиция «служителя

${ }^{3}$ Исключительность («эксклюзивность»), уверенность в себе и своем деле, забота о людях, хорошее знание их проблем, стремление улучшать жизнь, умение влиять на людей, решительность, провоцирование положительных эмоций. общества», забота о людях, хорошее знание их проблем, стремление улучшать жизнь. Примером влияния одежды на общественное мнение могут служить появления на публике вице-мэра Москвы по вопросам социального развития ${ }^{4}$. Стоимость ее гардероба, продемонстрированного на десяти официальных публичных мероприятиях, оценивается в 3 млн руб. (стоимость 7 пиджаков одного из самых дорогих в мире брендов Kiton варьируется от 160 до 507 тыс. руб., водолазка - 85 тыс. руб., футболка Brunello Cocinello - 46 тыс. руб., туфли Jimmy Choo - 45,3 тыс. руб., туфли Lois Vuitton - 70 тыс. руб., шарфик Chanel - 77 тыс. руб., ремень Loro Piano - 52 тыс. руб., пальто Loro Piano - 448 тыс. руб. $)^{5}$. Учитывая, что целевой аудиторией являются врачи, учителя, ветераны, сироты, дети из неблагополучных семей, инвалиды, малоимущие, можно предположить их восприятие и принятие как собственно информации, так и сотрудника. В этом случае сложно ожидать положительную реакцию на обещаемые вице-мэром выплаты пенсионерам в размере 4 тыс. руб. траншем по 2 тыс. руб. Да и информация о прожиточном минимуме москвичей в 16843 руб. на этом фоне выглядит далеко не позитивно. Подобная деятельность вице-мэра автоматически формирует коммуникативный барьер. Ситуация усугубилась повышенным вниманием оппозиционных СМИ, оперативно и массово распространивших информацию о модном аутфите государственной служащей в социальных сетях. Как известно, наиболее активными пользователями являются молодые люди (школьники, студенты и т. п.), а размещенная информация не только формирует негативный образ власти, воспроизводит реакцию отторжения, но и побуждает к протестным действиям, что и продемонстрировали события января 2021.

Одежда - это первый сигнал восприятия государственного служащего. Когда он встречается с аудиторией, у которой заведомо известный невысокий уровень жизни, в одежде дорогих брендов, то высока вероятность возникновения коммуникационного барьера. Для предотвращения подобных ситуаций рекомендуется использовать нейтральный или консервативный дресс-код. Высокий коэффициент консерватизма предписывает государственным служащим следующее.

${ }^{4}$ URL: https//youtu.be/GpseNko-JU

${ }^{5}$ Цены взяты из официального каталога ЦУМа города Москва. 
Организации со средним коэффициентом консервативности рекомендуют мужчинам костюм из натуральной ткани (зимой - шерсть, летом - лен), несколько рубашек светлых тонов и галстук.

Женщинам советуют носить костюмы (им отдается предпочтение), платья, блузоны, трикотажные шерстяные или хлопчатобумажные пуловеры. Чулки (колготы) телесного цвета без рисунка.

Цвета отдельных элементов одежды должны сочетаться, недопустимы яркие оттенки, резкие контрастные сочетания.

Макияж не обязателен, но приветствуется (тушь, румяна, губная помада). Желательно, чтобы украшения составляли комплект или были из одного материала (золото, серебро и т. п.). Отметим, что для государственных служащих даже самого высокого ранга украшения в настоящий момент крайне нежелательны.

Требования к дресс-коду организаций с низким коэффициентом консервативности менее жесткие. Но они тоже существуют: запрещается носить джинсы, спортивные кофты, яркую асимметричную одежду, одежду с оголенными частями тела (спина, грудь и т. п.). Менее жесткие требования к прическе (разрешены распущенные волосы) и макияжу. За нарушение правил дресс-кода не увольняют, но дают понять, что стиль одежды связан с перспективами работы.

В целях формирования адекватного габитарного имиджа сотрудника органов власти мы рекомендуем сформировать гардероб из двух частей. Первая - одежда в деловом стиле. Эта часть важна как для традиционных способов взаимодействия с общественностью (официальные приемы, встречи), так и для альтернативных способов (референдум; ежегодные доклады; награды, получаемые гражданами, и награды от групп населения, получаемые чиновниками). Для делового стиля рекомендуется несколько базовых вещей: классические черные брюки, юбка-карандаш, пуловер (желательно черный с V-образным вырезом), джемпер, несколько блузок. Аксессуары: сумка (желательно, но не обязательно, кожаная), нитка жемчуга, брошь, шейный платок.

Вторая часть гардероба - одежда в городском стиле. Она весьма полезна для таких способов альтернативного взаимодействия, как связи с местными ассоциациями; культурные мероприятия (поход, экскурсия, вечер и т. п.). Вот здесь фантазию, возможности и вкус можно проявить в полной мере. Окружающие это заметят, оценят, запомнят и, скорее всего, ваш авторитет укрепится: сотрудник, следящий и следующий за модными тенденциями, автоматически вызывает аттракцию и симпатию. Если сотрудник администрации появляется перед аудиторией растрепанным и мятым, неизбежно возникает вопрос: «Какой порядок может навести этот человек, как он может эффективно влиять на ситуации, если не может совладать с собственным гардеробом?!». Возможна и другая ситуация: идеально выдержанная одежда, отвечающая высокому коэффициенту консерватизма, может спровоцировать нежелательную реакцию отторжения, например, на встрече с малоимущими гражданами. Вот в этом случае городской стиль не только уместен, но и эффективен, поскольку позволит снизить возможное напряжение или негативное восприятие. Люди инстинктивно тянутся к тем, кого ассоциируют со своей общностью. Также они склонны наделять негативными качествами тех, кто вызывает недоверие. Это очень важный момент в планировании коммуникационного поля властных структур.

Составляя гардероб, следует помнить ряд правил:

- сочетание натуральных украшений с деловой одеждой считается моветоном. Подчеркнуть финансовое положение может дорогая бижутерия, часы, заколка для галстука, однако это недопустимо для встреч с общественностью;

- обувь претендента на высокий статусный уровень должна быть, во-первых, из натурального материала, во-вторых, с закрытым носком и пяткой, в-третьих, из одного вида материала (кожа), в-четвертых, высота каблука и его форма - умеренная, в-пятых, светлая обувь допустима до 17 ч., в-шестых, рекомендуемая форма туфель для женщин - классическая «лодочка».

Аксессуары, определяющие статус носителя: сумка; часы; перчатки; косынки и шарфы; ремни и ремешки; телефон и планшет.

Мужской вариант дресс-кода государственного служащего включает:

- костюм (двойка или тройка), при этом цвет и материал должны быть одинаковы, цвет темно-синий;

- пиджак: длина рукава должна доходить до основания большого пальца, воротник обязательно «английский», ткань натуральная;

- брюки - прямого покроя, длина такая, чтобы над обувью образовалась небольшая складка. Самое главное, чтобы брюки были отглажены, а стрелки идеально ровными. 


\section{Заключение}

В ряду коммуникационных провалов не последнее место в настоящее время занимает отсутствие или слабое продвижение положительного имиджа государственных структур. Особенно важно, что распространению препятствует низкий уровень доверия масс. Доверие во многом зависит от личного восприятия как структуры в целом, так и ее конкретных представителей, т. е. государственных служащих. В силу этого мы рекомендуем использовать комплексный имидж. Формирование комплексного имиджа позволяет повысить доверие населения за счет:

- трансформации распространенной в обществе модели неприятия (противостояния) властных структур, что существенно сглаживает культурно-исторические проблемы недоверия органам власти;

- роста квалификации сотрудников, осуществляющих связи с общественностью (устранение организационной проблемы), т. е.ликвидацию организационных проблем;

- формирования эффективной коммуникации «орган власти - общественность».

Таким образом, можно говорить о комплексном подходе к решению групп проблем, снижающих уровень доверия к деятельности органов государственной власти, прежде всего законодательной и исполнительной.

При разработке позитивного имиджа были учтены наиболее распространенные ошибки: отсутствие гибкости, недооценка фактора времени, недостаточная корректность в общении с общественностью. Для повышения доверия положительный образ должен включать такие востребованные обществом характеристики, как доступность, информационная открытость, компетентность, законность.

Корпоративный имидж может изменить стереотипное восприятие госструктуры за счет позиционирования характеристик «открытость», «законность», «доступность». Их формированию служат этапы алгоритма разработки имиджа «философия», «легенда», «окружение», «враги». Однако мы возлагаем особые надежды на действенность персонального имиджа, по-

\section{Библиографический список}

1. Арутюнян К. С. Факторы формирования общественного сознания в современных условиях // Вестник Северного (Арктического) федерального университета. Серия : Гуманитарные и социологические науки. 2019. № 3. C. 80-87. DOI: 10.17238/ issn2227-6564.2019.3.80. скольку именно сотрудники государственных структур осуществляют коммуникативное взаимодействие и именно от того, насколько верно выстроен их имидж, зависит оценочное мнение населения, а следовательно, степень доверия. При разработке технологии формирования персонального имиджа были учтены характеристики представителей властных структур, создающие коммуникационные барьеры общения: агрессивный тон, склонность к конфронтации, использование туманных двусмысленных фраз, раздражающе действующих на аудиторию (особенно в кризисных ситуациях), уход от прямых убедительных ответов, создающий впечатление о низкой степени компетентности или ее полном отсутствии. Устранить эти недостатки можно с помощью вербального имиджа.

Разработка адекватного, гибкого габитарного имиджа позволит усилить аттракцию между общественностью и представителями государственных структур, формируя мнение «один из нас», а не создавая коммуникационную пропасть.

Акцентирование внимания на разработке вербального и габитарного имиджа позволяет направить усилия на устранение или нивелирование указанных нежелательных характеристик и тем самым избежать ситуаций отторжения, полного либо частичного неприятия, что положительно влияет на степень аттракции. Кроме того, адекватный вербальный и габитарный имидж приводят в положительным изменениям априорного имиджа, отражающего культурно-историческую модель неприятия деятельности властных структур, к сожалению, все еще действующую в нашей стране.

Полагаем излишним приводить дополнительные аргументы в пользу того, что усиление внимания к габитарному и вербальному имиджу улучшит восприятие государственного служащего и позволит добиться высоких позиций в рейтинге доверия населения.

\section{Конфликт интересов}

Автор декларирует отсутствие явных и потенциальных конфликтов интересов, связанных с публикацией настоящей статьи.

2. Гуров Ф. PR IT-компаний: российская практика. М. : Альпина Паблишер, 2016.

3. Зайцева М. В., Кононенко А. И. Формирование позитивного имиджа муниципальных служащих в сознании жителей // Integral. 2018. № 4. С. 457-462.

4. Ильченко Д. А., Майкова В. П. Влияние СМИ и Интернета на формирование общественного со- 
знания в современной России // Вестник Московского государственного областного университета. Серия: Философские науки. 2018. № 4. С. 17-25. DOI: $10.18384 / 2310-7227-2018-4-17-25$

5. Кара-Мурза С. Г. Манипуляция сознанием. XXI век. М. : Аспект Пресс, 2004.

6. Кара-Мурза С. Г. Манипуляция сознанием. М. : Эксмо, 2009.

7. Колесников А. Спичрайтеры: Хроника профессии, сочинявшей и изменявшей мир. М. : Хранитель, 2007.

8. Комиссарова А. В. Воздействие на общественность и общественное мнение с целью управления общественными отношениями // Современные научные исследования: актуальные вопросы, достижения и инновации. 2017. С. 252-258.

9. Логвинова Т. В. Связи с общественностью в системе государственного управления // Ученые записки Тамбовского отделения РоСМУ. 2015. № 4. C. $40-45$.

10. Мишон E. В. Связи с общественностью в органах власти. М. : КНОРУС, 2018.

11. Мишон E. В. Управление общественными отношениями в кризисных ситуациях. М. : РУСАЙНС, 2017.

12. Мишон E. В. Управление общественными отношениями в современном обществе. Воронеж : Издательский дом ВГУ, 2017.

13. Молодов О.Б. Имидж регионального органа власти: теоретические основы и проблемы формирования // Вопросы теоретического развития. 2014. № 10 (20). C. 1-12.

14. Панасюк А. Ю. Формирование имиджа: стратегия, психотехнологии, психотехники. М. : Омега-Л, 2008.

15. Пиз А., Пиз Б. Говорите точно... Как соединить радость общения и пользу убеждения / пер. с англ. Т. О. Новиковой. М. : Эксмо, 2015.
16. Полухина И. В. Информационно-аналитическое обеспечение управления финансовыми результатами экономического субъекта // Вестник Воронежского государственного университета. Серия: Экономика и управление. 2020. № 2. С. 90-104. DOI: 10.17308/econ.2020.2/2904

17. Роговая А. В., Маркин В. В., Чумиков А. Н. Практика информационной деятельности по нейтрализации распространения идеологии терроризма // Вестник Национального антитеррористического комитета. 2013. № 2 (09). С. 45-54.

18. Рокотянская В. В. Управление общественным мнением в современной России // Проблемы экономики и юридической практики. 2018. № 5. С. 43-47.

19. Симонова М. В. Управление производительностью труда в системе компетенций на региональном уровне // Вестник Воронежского государственного университета. Серия: Экономика и управление. 2020. № 4. C. 83-91. DOI: 10.17308/ econ.2020.4/3196

20. Фоменко В. И., Дубова Ю. И. Организация эффективной деятельности по связям с общественность в органах муниципальной власти // Научный альманах. 2016. № 12. С. 292-294.

21. Чумиков А. Н., Бочаров М. А. Государственный PR: связи с общественностью для государственных организаций и проектов. М. : Инфра-М, 2012.

22. Чумиков А. Н. Альтернативная гражданская служба как особый вид трудовой деятельности, право гражданина и способ заполнения непопулярных рабочих мест: современные проблемы и варианты их решения // Будущее сферы труда: глобальные вызовы и региональное развитие : сборник статей Международного форума «Будущее сферы труда: достойный труд для всех». Уфа : Мир Печати, 2019. С. 344-349.

Мишон Елена Витальевна, доктор экономических наук, профессор кафедры региональной экономики и территориального управлеПоступила в редакциию 15.01.2021 ния, Воронежский государственный универсиПодписана в печать 18.02.2021 тет, Воронеж, Российская Федерация

E-mail:mishon@econ.vsu.ru

ORCID ID: 0000-0002-6939-8016 


\title{
Comprehensive image of state power as a tool of social management
}

\author{
E. V. Mishon ${ }^{1 凶}$ \\ ${ }^{1}$ Voronezh State University, 1 University sq., 394018 Voronezh, Russian Federation
}

Cite as: Mishon, E. V. (2021) Comprehensive image of state power as a tool of social management. Proceedings of the Voronezh State University. Series: Economics and Management. 1, 76-85. (In Russ., abstract in Eng.). DOI: 10.17308/econ.2021.1/3326

\begin{abstract}
Importance. The practice of recent years clearly demonstrates the tendency of the population to decline in confidence in the activities of the authorities. The further development of this process is unacceptable, since in such a case the work of all state structures becomes ineffective even if it is absolutely expedient and justified. The reasons for public distrust of the authorities can be divided into three groups: communicative, organizational and cultural-historical problems. Communicative problems arise due to violations or disregard for the requirements of communication theory. Organizational difficulties in the vast majority of cases are associated with the low qualification of specialists responsible for interacting with society (usually PR specialists or public relations specialists). Cultural and historical problems are due to the dominance in our society of an established model of behavior of citizens, which stably reproduces the situation of opposition to the authorities. In our opinion, the most significant group communication problems - requires priority attention.

Perpose. Communication problems arise from the misplaced positioning of power structures, that is, from the inability to clearly and arguably explain the significance and appropriateness of planned or already implemented measures. Accordingly, it is necessary to identify/develop, in a short time, technologies, methods and tools to eliminate communication barriers, and in some cases communication failures, public-governmental interactions.

Research methodology. To achieve the goal, the author's approach was applied, which is based on the principles of systematics, flexibility, mobility and adequacy (they served as the basis for the need to develop an integrated image). The theoretical base is the works of domestic and foreign scientists in the field of public relations management. Methods for the study of soft systems are used: theoretical typology, formal extrapolation, factographic methods based on information analysis (analogy method, content analysis), forsyth modeling (technology for working with images of the future.

Results. In order to increase the rating of public confidence in the activities of state structures based on the study, systematization and analysis of the causes and consequences of communicative failures and barriers to effective interaction between these switches, an approach based on the principles proposed by the author (systematics, adequacy, flexibility, mobility) and the use of such a social management tool as image is proposed. An option of developing a comprehensive image of the state structure, including a corporate and personal image, has been proposed and justified. Its development technology is recommended, providing an integrated approach to solving the problem of effective interaction using modern public relations management tools.
\end{abstract}

Key words: communication barrier, trust rating, corporate image, personal image, gabitarian image, verbal image.

\section{Conflict of Interest}

The author declares that there are no clear and potential conflicts of interest related to the publication of this article. 


\section{References}

1. Harutyunyan, K. S. (2019) Factors of the formation of social consciousness in modern conditions. Bulletin of the Northern (Arctic) Federal University. Series: Humanitarian and Sociological Science. 3, 80-87. DOI: 10 17238/issn2227-6564.2019.3.80 (In Russian).

2. Gurov, F. (2016) [PR in IT companies: Russian practice]. Moscow, Alpina Publisher. (In Russian).

3. Zaitseva, M. V. \& Kononenko, A. I. (2018) Formation of a positive image of municipal employees in the minds of residents. International Journal of Applied Sciences and Technologies "Integral". 4, 457-462. (In Russian).

4. Ilchenko, D. A. \& Maykova, V. P. (2018) The influence of the media and the Internet on the formation of public consciousness in modern Russia. Bulletin of Moscow State Regional University. Series: Philosophical Sciences. 4, 17-25. DOI: 10.18384/2310-7227-2018-417-25 (In Russian).

5. Kara-Murza, S. G. (2004) Manipulation of consciousness. XXI century. Moscow, Aspect Press publ. (In Russian).

6. Kara-Murza, S. G. (2009) [Manipulation of consciousness]. Moscow, Eksmo publ. (In Russian).

7. Kolesnikov, A. (2007) Speechwriters: Chronicle of the profession that composed and changed the world. Moscow, Khranitel publ. (In Russian).

8. Komissarova, A. V. (2017) Impact on public and public opinion with purpose of public relationship management. Modern scientific research: topical issues, achievements and innovations. 252-258. (In Russian).

9. Logvinova, T. V. (2015) Public relations in the public administration system. Scientific notes of the Tambov branch of RoSMU. 4, 40-45. (In Russian).

10. Mishon, E. V. (2018) [Public Relations in the Authorities]. Moscow, KNORUS publ. (In Russian).

11. Mishon, E. V. (2017) [Management of public relations under crisis conditions]. Moscow, RUSAINS publ. (In Russian).

12. Mishon, E. V. (2017) [Management of Public Relations in Modern Society]. Voronezh, Publishing House of VSU. (In Russian).
13. Molodov, O. B. (2014) Image of the regional authority: theoretical foundations and problems of formation. Issues of theoretical development. 10 (20), 1-12. (In Russian).

14. Panasyuk, A. Yu. (2008) [Image formation: strategy, psychotechnology, psychotechnics]. Moscow, Omega-L publ. (In Russian).

15. Peace, A. \& Garner, A. (1985) Talk Language. Pease Training Corporation publ.

16. Polukhina, I. V. (2020) Information and analytical support for financial results management in companies. Proceedings of Voronezh State University. Series: Economics and Management. 2, 90-104. (In Russian) DOI: 10.17308/econ.2020.2/2904 (In Russian).

17. Rogovaya A. V., Markin V. V. \& Chumikov A. N. (2013) Practice of information activities to neutralize the spread of the ideology of terrorism. Bulletin of the National Anti-Terrorism Committee. 2(09), 45-54. (In Russian).

18. Rokotyanskaya, V. V. (2019) Public Opinion Management in Modern Russia. Problems of Economics and Legal Practice. 5, 43-47. (In Russian).

19. Simonova, M. V. (2020) Labor productivity management in the competence system at the regional level. Proceedings of Voronezh State University. Series: Economics and Management. 4, 83-91. (In Russian) DOI: 10.17308/econ.2020.4/3196 (In Russian).

20. Fomenko, V. I. \& Dubova, Yu. I. (2016) Organization of effective public relations activities in municipal authorities. Scientific Almanac. 12, 292-294. (In Russian).

21. Chumikov, A. N. \& Bocharov, M. A. (2012) State PR: public relations for state organizations and projects. Moscow, Infra-M publ. (In Russian).

22. Chumikov, A. N. (2019) Alternative civil service as a special type of labor activity, the right of a citizen and the way to fill unpopular jobs: modern problems and solutions to them. Future of the labor sector: global challenges and regional development: a collection of articles of the International Forum "The Future of the Labor Sector: Decent Work for All". Ufa, World of the Press, 344-349. (In Russian).
Elena V. Mishon, Dr. Sci (Econ.), Full Prof., Regional Economics and Territorial Management Department, Voronezh State University, Voronezh, Russian Federation

E-mail: mishon@econ.vsu.ru

ORCID ID: 0000-0002-6939-8016
Received 15.01.2021

Accepted 18.02.2021 